\title{
Fungos micorrízicos arbusculares e doses de fósforo no desenvolvimento de mudas de guanandi
}

\author{
Edilson Nonato da SILVA ${ }^{1}$, Aline Torquato TAVARES ${ }^{1 *}$, Cândida Pereira da SILVA ${ }^{1}$, Tiago Alves FERREIRA ${ }^{1}$, \\ João Victor Gonçalves CARLINE ${ }^{1}$, Ildon Rodrigues NASCIMENTO ${ }^{1}$ \\ ${ }^{1}$ Universidade Federal do Tocantins, Gurupi, TO, Brasil. \\ *E-mail: alinet4t@hotmail.com
}

Recebido em março/2017; Aceito em março/2018.

RESUMO: O experimento foi realizado na Estação Experimental de Engenharia Florestal do Campus Universitário de Gurupi, Universidade Federal do Tocantins (UFT), com objetivo de determinar a melhor dose de fósforo na presença de fungos arbusculares em mudas de guanandi (Calophyllum brasiliense Camb.) $\mathrm{O}$ delineamento experimental utilizado foi inteiramente casualizado com três repetições em esquema fatorial $6 \mathrm{x}$ 2. Os tratamentos foram seis doses de fósforo $\left(0 ; 400 ; 800 ; 1200 ; 1600\right.$ e $2000 \mathrm{~g} \mathrm{de} \mathrm{P}_{2} \mathrm{O}_{5}$ por $\left.\mathrm{m}^{3}\right)$ no substrato na presença e ausência de Fungos Micorrízos Arbusculares (FMAs). As características avaliadas foram altura das plantas, diâmetro do caule, massa seca da parte aérea (MSPA), massa seca da raiz (MSR), massa seca total (MST) e colonização micorrízica. Os diferentes níveis de adubação influenciaram a colonização micorrízica arbuscular. Nas doses 400 e $1600 \mathrm{~g}$ de fósforo por $\mathrm{m}^{3}$ de substrato observou-se maior porcentagem de colonização. A altura e o diâmetro das plantas foram significativamente afetados pela presença de $\mathrm{P}_{2} \mathrm{O}_{5}$. A massa seca da parte aérea e massa seca total não é afetada por doses de $\mathrm{P}_{2} \mathrm{O}_{5}$. O melhor desempenho das mudas de C. brasiliense ocorreu aos 90 dias com dose de $1.421 \mathrm{~g}$ de $\mathrm{P}_{2} \mathrm{O}_{5}$ por $\mathrm{m}^{3}$ de substrato.

Palavras-chave: Calophyllum brasiliense Camb., adubação, micorrização.

\section{Mycorrhizal fungi and phosphorus doses in the development of guanandi seedlings}

\begin{abstract}
The experiment was carried out at the Forest Engineering Experimental Station of the Federal University of Tocantins (UFT), University Campus of Gurupi, with the objective of determining the best dose of phosphorus in the presence of arbuscular fungi in guanandi (Calophyllum brasiliense Camb. The experimental design was completely randomized with three replicates in a $6 \times 2$ factorial scheme. The treatments were six doses of phosphorus $\left(0,400,800,1200,1600\right.$ and $2000 \mathrm{~g}$ of $\mathrm{P}_{2} \mathrm{O}_{5}$ per $\left.\mathrm{m}^{3}\right)$ on the substrate in the presence and absence of Arbuscular mycorrhizal fungi (FMAs). The evaluated characteristics were plant height, stem diameter, shoot dry mass (MSPA), root dry mass (MSR), total dry mass (MST) and mycorrhizal colonization. The different levels of fertilization influenced arbuscular mycorrhizal colonization. At 400 and $1600 \mathrm{~g}$ of phosphorus per $\mathrm{m}^{3}$ of substrate, a higher percentage of colonization was observed. The height and diameter of the plants were significantly affected by the presence of P2O5. Dry shoot mass and total dry mass are not affected by $\mathrm{P} 2 \mathrm{O} 5$ doses. The best performance of $C$. brasiliense seedlings occurred at 90 days with a dose of $1421 \mathrm{~g}$ of $\mathrm{P} 2 \mathrm{O} 5$ per $\mathrm{m} 3$ of substrate.
\end{abstract}

Keywords: Calophyllum brasiliense Camb., fertilization, mycorrhization.

\section{INTRODUÇ̃̃O}

O Calophyllum brasiliense Camb., é uma espécie pertencente a família Clusiaceae, conhecido popularmente como guanandi, landi, jacareúba, guanandi-carvalho e guanandi cedro, possui potencial de uso em projetos de reflorestamento para fins econômicos, entretanto, é necessário mais estudos sobre sua produção de mudas (LISBOA et al., 2012). É uma espécie florestal de grande porte (atinge 30 a $40 \mathrm{~m}$ de altura), de característica perenifólia, heliófita ou de luz difusa, ocorre exclusivamente em solos úmidos e brejosos. Essa espécie possui um grande potencial madeireiro, sobretudo pela característica de sua madeira para a indústria moveleira e para o uso naval (CIRIELLO et al., 2014).

A propagação do $C$. brasiliense Camb. é feita por sementes, porém são escassos os trabalhos relacionados com a qualidade das sementes, produção de mudas, manejo e exigências nutricionais.
Para atender a crescente demanda de madeira, com características tecnológicas exigidas para os diversos usos, torna-se necessário a produção de mudas padronizadas para suprir as exigências do mercado. Nesse sentido, esforços consideráveis têm sido feitos pelos pesquisadores florestais no intuito de definir métodos e técnicas de produção de alto padrão de qualidade com custos reduzidos.

A deficiência nutricional limita a produção de mudas, principalmente nas regiões tropicais e subtropicais, pois nessas regiões predominam solos velhos e imtemperizados (NOVAIS et al., 1999), e as plantas não absorvem $10 \%$ do fósforo total aplicado via adubação (MALAVOLTA et al., 1989).

$\mathrm{Na}$ busca de uma maximização da adubação fosfatada, alternativas biológicas como a utilização de fungos micorrízicos arbusculares (FMAs) têm sido uma opção para minimizar o problema (CARNEIRO et al., 2009). Por meio dessa associação, a planta fornece ao fungo os carboidratos 
necessários ao seu crescimento, enquanto que este último, por meio de suas estruturas externas (hifas), auxilia a planta na absorção dos nutrientes, principalmente do fósforo (SILVA et al., 2009).

Lucena (2013) observou que plantas de paricá (Schizolobium amazonicum), apresentaram maior crescimento quando inoculas com espécies de FMAs. Aguiar et al. (2004) verificaram resposta positiva da inoculação dos FMAs na algaroba (Prosopis juliflora DC), principalmente na altura, diâmetro do colo e no número de folhas.

Diante do exposto, objetivou-se determinar a melhor dose de fósforo na presença de fungos arbusculares em mudas de guanandi (Calophyllum brasiliense Camb.).

\section{MATERIAL E MÉTODOS}

O experimento foi conduzido no Setor de Engenharia Florestal da Estação Experimental do Campus Universitário de Gurupi, Universidade Federal do Tocantins - UFT, situado na latitude sul $11^{\circ} 43^{\prime} 45^{\prime \prime}$ e longitude oeste 49 $04^{\prime} 07^{\prime}$ ' com altitude de $280 \mathrm{~m}$. A classificação climática para a região, segundo Koppen, (1948) é do tipo Aw, ou seja, clima tropical com estação seca. A precipitação média anual da região situa-se em torno de $1500 \mathrm{~mm}$ e a temperatura média anual, em torno dos $27{ }^{\circ} \mathrm{C}$, com média máxima de $35^{\circ} \mathrm{C}$ e média mínima de $18^{\circ} \mathrm{C}$.

As sementes de guanandi foram coletadas no Assentamento Lago Verde, localizado no município de Lagoa da Confusão - TO. Foram coletados frutos que caíam naturalmente de três árvores matrizes sadias, vigorosas e em plena maturidade. A quantidade de frutos coletados não excedeu $50 \%$ em cada matriz, número estipulado pela equipe para garantir frutos.

Após a coleta dos frutos de guanandi, retirou-se a polpa, escarificou as sementes com lixa. A semeadura foi realizada em substrato compostos de areia lavada na profundidade de 2 $\mathrm{cm}$. No momento em que as plântulas atingiram cerca de 10 $\mathrm{cm}$ de altura foram transplantadas para os sacos polietileno com dimensões 0,18 x 0,30 m com capacidade de $1,50 \mathrm{~kg}$. $\mathrm{O}$ substrato foi composto por solo e areia, na proporção 2:1, onde permaneceram até o final do período experimental (120 dias).

O substrato utilizado foi solo de barranco com a seguinte composição química: $\mathrm{pH}$ (água) $=4,9 ; \mathrm{P}=4,9 \mathrm{mg} / \mathrm{dm}^{-3} ; \mathrm{K}=$ $0,09 \mathrm{mg} \mathrm{dm}^{-3} ; \mathrm{Ca}=1,9 \mathrm{cmol}_{\mathrm{c}} / \mathrm{dm}^{-3} ; \mathrm{Al}=0,0 \mathrm{cmol}_{\mathrm{c}} / \mathrm{dm}^{-3}$; $\mathrm{SB}=3,3 ; \mathrm{MO}=3,0 \% ;$ Areia $=65 \%$; Silte $=7,1 ;$ Argila $=27,8 \%$ e $\mathrm{V} \%=44,10$. O substrato foi esterilizado por solarização por um período de oito dias em lona plástica de coloração preta. $\mathrm{Na}$ adubação de base e pós-plantio utilizou-se a recomendação de adubação para produção de mudas de eucaliptos (SCHORN, 2003), devido a carência de informações para a espécie em estudo. Adubou-se com $150 \mathrm{~g}$ de $\mathrm{N}$ (na forma de Uréia) e $100 \mathrm{~g}$ de $\mathrm{K}_{2} \mathrm{O}$ (na forma de Cloreto de Potássio) por $\mathrm{m}^{3}$ de substrato.

A adubação com $\mathrm{P}_{2} \mathrm{O}_{5}$ foi feita em doses crescentes de fósforo na forma de Superfosfato Simples. As adubações de pós-plantio foram realizadas com $3 g$ de Nitrogênio e $2 g$ de $\mathrm{K}_{2} \mathrm{O}$ por planta. Durante a condução do experimento manteve-se a umidade do solo na capacidade de campo com irrigações diárias.

$\mathrm{O}$ delineamento experimental utilizado foi inteiramente casualizado com três repetições e nove plantas por parcelas em esquema fatorial $6 \times 2$, sendo: seis doses de fósforo aplicadas na forma de superfosfato simples $(0 ; 400 ; 800$; $1200 ; 1600$ e $2000 \mathrm{~g}$ de $\mathrm{P}_{2} \mathrm{O}_{5} \mathrm{~m}^{-3}$ de substrato) na presença e ausência de Fungos Micorrízos Arbusculares (FMAs).

A inoculação foi realizada com uma mistura de FMAs (Glomusclarum, Scutellospora Calospora e Glomus etunicatum), utilizando-se $0,5 \mathrm{~g}$ de inoculo por planta, com cerca de 160 esporos por espécie de FMA, obtidos da Embrapa Agrobiologia. A inoculação com FMA foi realizada no momento do plantio misturado ao substrato, depositados em contato direto com a raiz da plântula no transplantio.

Após 30, 60 e 90 dias, avaliou-se as seguintes características: altura das plantas $(\mathrm{H}$ em $\mathrm{cm})$, diâmetro do caule (D em mm) (com paquímetro digital de precisão de $0,001 \mathrm{~mm}$ ). Aos 120 dias foi avaliada a colonização micorrízica, massa seca da parte aérea (MSPA), massa seca da raiz (MSR) e massa seca total (MST). A taxa de colonização micorrízica no sistema radicular foi realizada segundo o método de Koske; Gemma (1989). As características massa seca da raiz (MSR); massa seca da parte aérea (MSPA) e massa seca total (MST) foram obtidas em estufa de circulação forçada de ar a $60^{\circ} \mathrm{C}$ até obter peso constante.

Com as médias de cada parcela realizou-se a análise de variância e análise de regressão com desdobramento da interação para efeito de dose na presença e ausência de FMAs. As análises foram feitas pelo programa estatístico Sisvar 5.3 (FERREIRA, 2010).

\section{RESULTADOS}

As porcentagens de colonização micorrízica nas mudas de guanandi (Calophyllum brasiliense Camb.), aos 120 dias após a inoculação com os fungos micorrízicos em diferentes doses de fósforo (Figura 1), é influenciado pela dose de fósforo, não sendo possível ajustar modelos que permitisse estimar um comportamento.

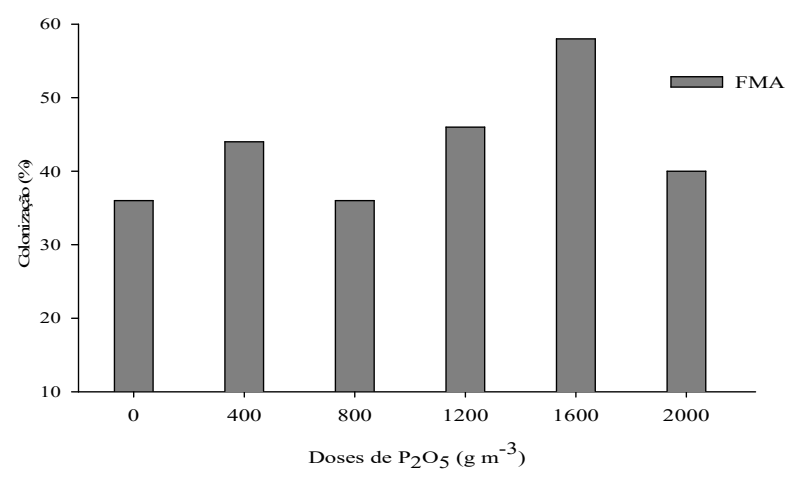

Figura 1. Porcentagem de colonização micorrízica de mudas de guanandi (Calophyllum brasiliense Camb.) aos 120 dias após a inoculação com os fungos micorrízicos em diferentes doses de fósforo. Gurupi, 2015.

Figure 1. Percentage of mycorrhizal colonization of guanandi (Calophyllum brasiliense Camb.) seedlings at 120 days after inoculation with mycorrhizal fungi at different doses of phosphorus. Gurupi, 2015.

A maior porcentagem de colonização ocorreu na dose $1600 \mathrm{~g}$ de $\mathrm{P}_{2} \mathrm{O}_{5}$, indicando que os diferentes níveis de adubação interferem na colonização micorrízica para a espécie em estudo. 
$\mathrm{Na}$ ausência de fungos FMAs, à medida que se aumentou as doses de fósforo no substrato, o diâmetro da muda foi cerca de 21,94\% superior, quando se compara com o tratamento onde não foi usado fósforo.

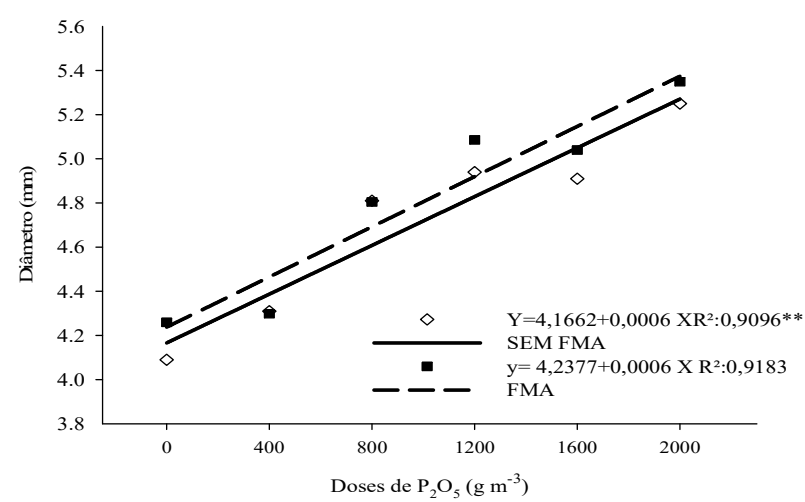

Figura 2. Crescimento do diâmetro de mudas de guanandi (Calophyllum brasiliense Camb.) influenciado pelas doses de fósforo na presença e ausência de fungos micorrizicos arbusculares (FMAs). Gurupi, 2015.

Figure 2. Growth of the diameter of guanandi seedlings (Calophyllum brasiliense Camb.) influenced by the doses of phosphorus in the presence and absence of arbuscular mycorrhizal fungi (AMF). Gurupi, 2015.

Houve uma resposta positiva no diâmetro das mudas até a dose de $2000 \mathrm{~g}$ de $\mathrm{P}_{2} \mathrm{O}_{5}$ na presença de FMAs, com valores superiores, quando comparado com os tratamentos na ausência de FMAs, com linha de tendência linear. Tanto na presença, quanto na ausência de FMAs, para cada grama de $\mathrm{P}_{2} \mathrm{O}_{5}$ adicionado ao substrato, houve incremento de $0,0006 \mathrm{~mm}$ no diâmetro médio das mudas, conforme pode ser observado na Figura 2.

Como pode-se observar na Figura 3, o desdobramento de época dentro dos níveis de FMAs utilizada, houve diferença no crescimento das mudas nas épocas 60 e 120 dias quando comparado com tratamento com ausência dos fungos, tendo um aumento no diâmetro das mudas de $4,40 \%$ aos 60 dias e 6,07 aos 120 dias.

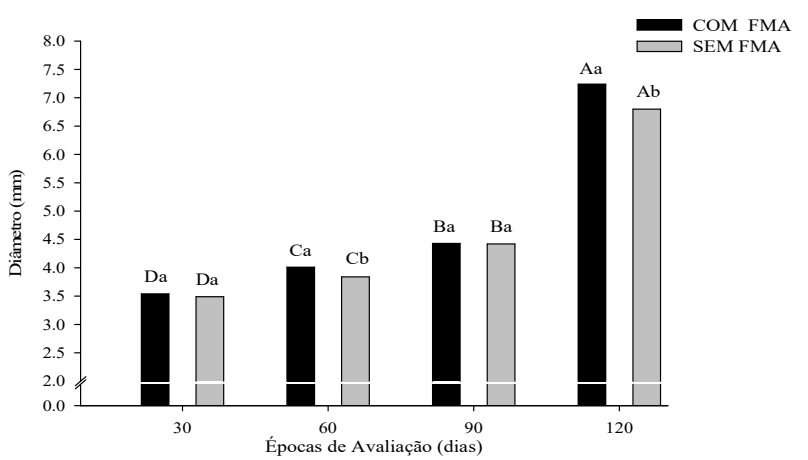

Figura 3. Diâmetro de mudas de guanandi (Calophyllum brasiliense Camb.) em quatro épocas avaliação, na ausência e presença de fungos micorrízicos arbusculares (FMAs). Significativo pelo teste de Tukey com $\mathrm{p}=0,05$. Gurupi, 2015.

Figure 3. Diameter of guanandi seedlings (Calophyllum brasiliense Camb.) In four seasons evaluation, in the absence and presence of arbuscular mycorrhizal fungi (AMF). Significant by the Tukey test with $\mathrm{p}=0.05$. Gurupi, 2015 .

A altura das mudas de guanandi nas diferentes doses de fósforo sob efeito de FMAs é observado na Figura 4, verifica-se um crescimento significativo das mudas na dose
$1200 \mathrm{~g} \mathrm{de} \mathrm{P}_{2} \mathrm{O}_{5}$, com incremento de $30,76 \%$ em relação ao tratamento que não foi aplicado $\mathrm{P}_{2} \mathrm{O}_{5}$.

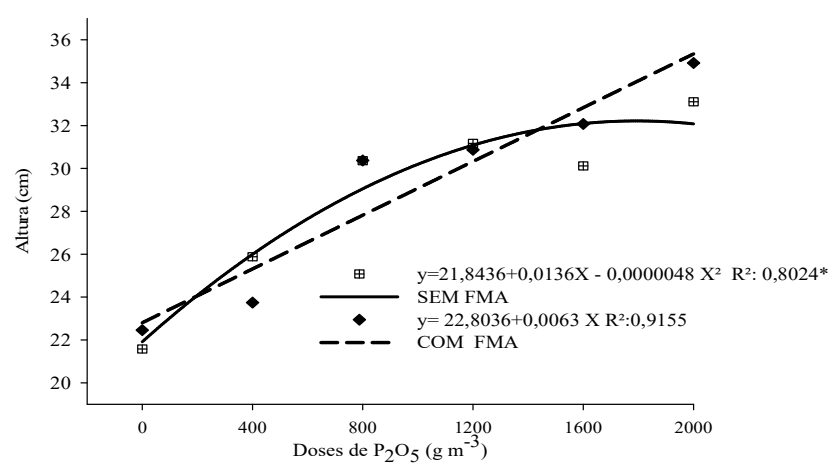

Figura 4. Altura de mudas de guanandi (Calophyllum brasiliense Camb.) em função de diferentes doses de $\mathrm{P}_{2} \mathrm{O}_{5}$ na presença e ausência de fungos micorrizicos arbusculares (FMAs). Gurupi, 2015.

Figure 4. Height of guanandi seedlings (Calophyllum brasiliense Camb.) in the a function of different doses of $\mathrm{P}_{2} \mathrm{O}_{5}$ in the presence and absence of arbuscular mycorrhizal fungi (AMF). Gurupi, 2015.

Houve efeito linear da altura das mudas em função das doses de $\mathrm{P}_{2} \mathrm{O}_{5}$ associada aos FMAs. No gráfico (Figura 4), pode-se observar a importância que os FMAs assumem, frente às diferentes doses de fósforos, para crescimento em altura de muda de guanandi, com incremento de $0,0063 \mathrm{~cm}$ para cada $\mathrm{g}$ de $\mathrm{P}_{2} \mathrm{O}_{5}$ aplicado na presença FMAs e de 0,0136 cm para cada g de $\mathrm{P}_{2} \mathrm{O}_{5}$ na ausência de FMAs. Em relação ao tratamento que não recebeu $\mathrm{P}_{2} \mathrm{O}_{5}$ a presença de FMAs proporcionou na presença de fósforo um incremento de cerca de $32,80 \%$ maior.

O desdobramento de época dentro do nível de fungos micorrizicos sobre altura de mudas de guanandi que descreve as condições morfofisiológicas das plantas em diferentes intervalos de tempo é observado na Figura 5.

$\mathrm{O}$ tratamento associado ao fungo diferiu significativamente em relação ao tratamento sem inoculação nas épocas 90 e 120 dias. Aos 90 dias as plantas associadas ao FMAs cresceram $18,5 \%$ a mais que o tratamento sem efeito da micorriza. Aos 120 dias essa diferença foi de $7,44 \%$. Nas demais épocas não houve diferença significativa.

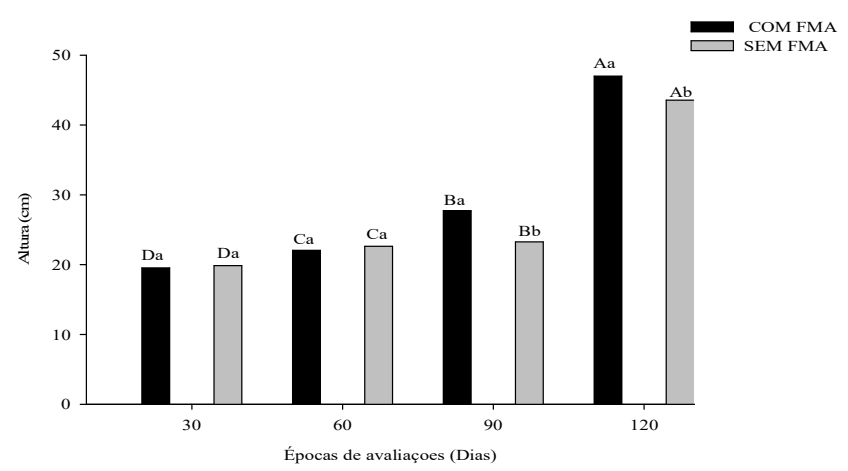

Figura 5. Altura de mudas de guanandi (Calophyllum brasiliense Camb.) em função do tempo, na presença de micorrízicos arbusculares (FMAs). Significativo pelo teste de Tukey com $\mathrm{p}=$ 0,05. Gurupi, 2015.

Figure 5. Height of guanandi seedlings (Calophyllum brasiliense Camb.) As a function of time, in the presence of arbuscular mycorrhizal (AMF). Significant by the Tukey test with $\mathrm{p}=0.05$. Gurupi, 2015. 


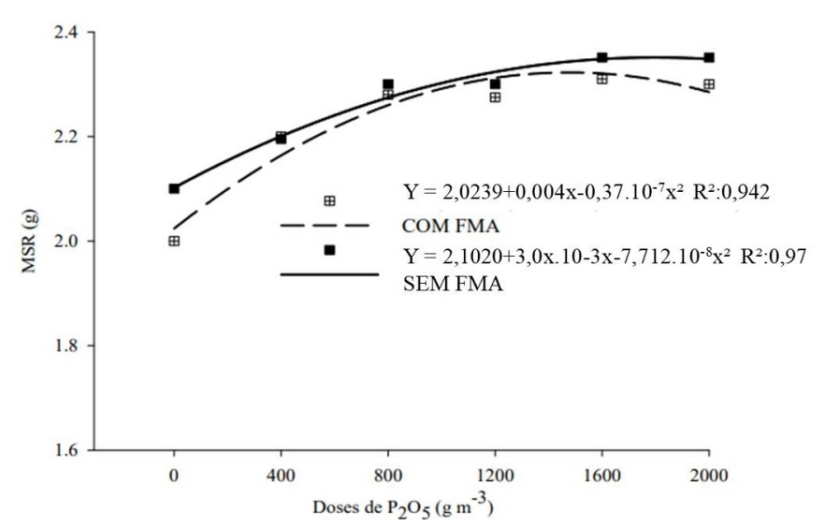

Figura 6. Massa seca da raiz (MSR) de mudas de guanandi (Calophyllum brasiliense Camb.) aos 120 dias em função de doses de $\mathrm{P}_{2} \mathrm{O}_{5}$ na presença e ausência de fungos micorrízicos arbusculares (FMAs). Gurupi, 2015.

Figure 6. Dry root mass (MSR) of guanandi (Calophyllum brasiliense Camb.) Seedlings at 120 days as a function of P2O5 doses in the presence and absence of arbuscular mycorrhizal fungi (AMF). Gurupi, 2015.

O crescimento da massa seca da parte aérea diferiu significativamente entre as doses de fósforo, apresentando resposta quadrática, com maior incremento na dose de $1200 \mathrm{~g}$ (Figura 7), não sendo observado diferença entre 1600 e 2000 $\mathrm{g}$ de $\mathrm{P}_{2} \mathrm{O}_{5}$ por $\mathrm{m}^{3}$ de substrato. Já a resposta das plantas inoculadas com as espécies de FMAs não proporcionou aumento na produção de massa seca da parte aérea.

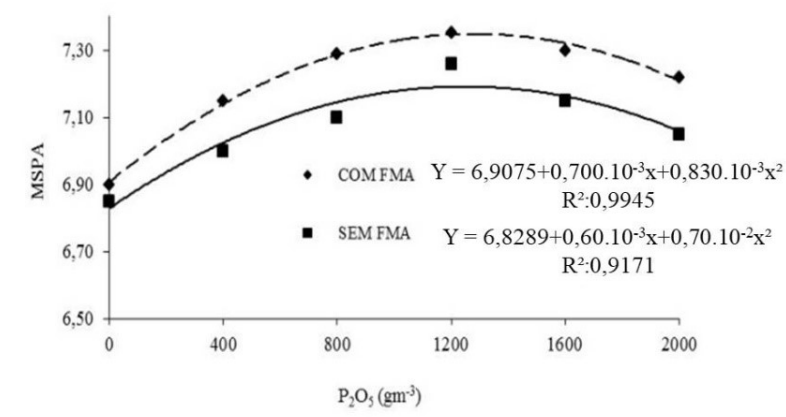

Figura 7. Massa seca da parte aérea (MSPA) de mudas de guanandi (Calophyllum brasiliense Camb.) aos 120 dias em função de doses de $\mathrm{P}_{2} \mathrm{O}_{5}$ na presença e ausência de fungos micorrízicos arbusculares (FMAs). Gurupi, 2015.

Figure 7. Dry shoot mass (MSPA) of guanandi (Calophyllum brasiliense Camb.) seedlings at 120 days as a function of $\mathrm{P}_{2} \mathrm{O}_{5}$ doses in the presence and absence of arbuscular mycorrhizal fungi (AMF). Gurupi, 2015.

Na figura 8 , observa-se que a produção de massa seca total das mudas de guanandi teve um crescimento com o aumento das doses 400, 800, 1200 e $1600 \mathrm{~g} \mathrm{de}_{2} \mathrm{O}_{5}$ por $\mathrm{m}^{3} \mathrm{de}$ substrato com maior incremento na dose de $1421 \mathrm{~g}$, a partir de então com crescimento constante até a dose de $2000 \mathrm{~g}$.

A regressão para massa seca total das mudas associada aos fungos micorrizicos arbuculares promoveu resposta tanto na presença quanto na ausência do fungo, com máxima resposta com doses variando entre 1200 e 1600. Esse mesmo padrão de resposta foi observado para massa seca da raiz e massa seca da parte aérea (Figuras 6 e 7).

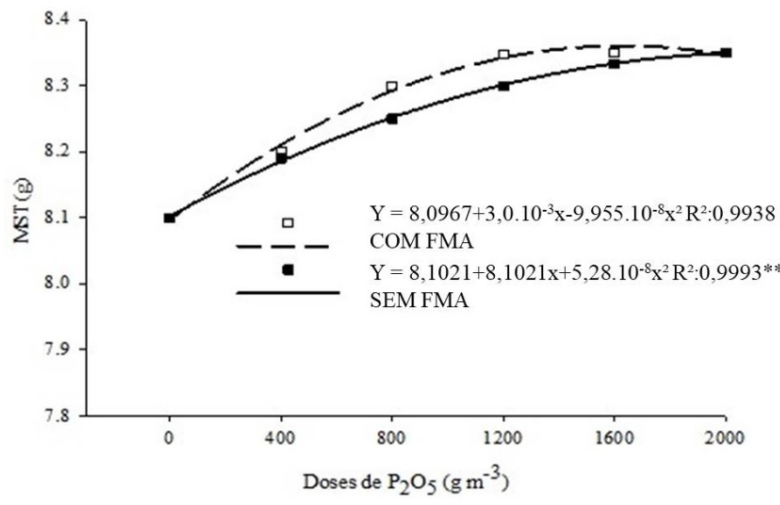

Figura 8. Massa seca total (MST) de mudas de guanandi (Calophyllum brasiliense Camb.) aos 120 dias em função de doses de $\mathrm{P}_{2} \mathrm{O}_{5}$ na presença e ausência de fungos micorrízicos arbusculares (FMAs). Gurupi, 2015.

Figure 8. Total dry mass of guanandi (Calophyllum brasiliense Camb.) Seedlings at 120 days as a function of $\mathrm{P} 2 \mathrm{O} 5$ doses in the presence and absence of arbuscular mycorrhizal fungi (AMF). Gurupi, 2015.

\section{DISCUSSÃO}

Pode-se observar que FMAs podem ser utilizados em programas de adubação para melhorar a qualidade de mudas de espécies florestais. Resultados semelhantes foram observados por Lacerda et al. (2011). Estes pesquisadores verificaram aumento em quase $70 \%$ em algumas espécies colonizadas por Glomus clarum em condição de alto fósforo.

Freitas et al. (2006), avaliando a inoculação de FMAs e doses de $\mathrm{P}$ em plantas de menta, observaram que nos tratamentos sem a adubação fosfatada $\left(6 \mathrm{mg} \mathrm{dm}^{-3}\right)$ obtiveram-se as maiores porcentagens de colonização micorrízica, correspondendo aos valores de 69 e $81 \%$, para os tratamentos com Glomus clarum e Gigaspora margarita, respectivamente, os quais proporcionaram maiores produções de massa fresca e seca da parte aérea.

Plantas que possuem sistema radicular pouco ramificado respondem a micorrização, mesmo quando o nível de fósforo é elevado no solo, o que justifica o resultado observado para presença de FMA, uma vez que o Guanandi possui sistema radicular profundo e pouco ramificado (SOUZA et al., 2011).

A eficiência do fósforo no crescimento do diâmetro de mudas foi observado também por Santos et al. (2008) que verificaram resposta linear positiva no diâmetro em mudas de mogno em função de doses crescentes de fósforo.

O diâmetro das mudas é uma das características mais importante nas quais se baseiam a classificação de mudas com alto padrão de qualidade (TRAZZI et al., 2012).

Segundo Duarte (2015), as mudas devem apresentar altos valores de diâmetros de colo para melhorar o equilíbrio do crescimento da parte aérea, ou seja, o maior diâmetro indica melhor captação e translocação de nutrientes na planta. Paron et al. (1997) observaram micotrofismo em mudas de trema na fase inicial de crescimento, entretanto, a micorrização não eliminou a necessidade de aplicação de fertilizante fosfatado, uma vez que em fase posterior, as plantas sem fósforo cresceram pouco, mesmo quando micorrizadas.

Daniel et al. (1997), em estudo com aplicação de fósforo em plantas de Acacia mangium Willd, com doses de 200, 400,600 e 800 g de $\mathrm{P}_{2} \mathrm{O}_{5} \mathrm{~m}^{-3}$ de substrato, constataram que a partir da dose de $400 \mathrm{~g} \mathrm{~m}^{-3}$ de $\mathrm{P}_{2} \mathrm{O}_{5}$ ocorreu um equilíbrio entre a rápida aceleração inicial do crescimento. 
As plantas superiores tem o seu crescimento beneficiado pela presença de micorizas, a FMAs, tem efeito benéfico independente da condição de cultivo (MUNIER-LAMY et al., 2007), isso pode justificar a eficiência dos fungos micorrizicos arbusculares no crescimento do diâmetro das mudas de guanandi aos 60 e 120 dias.

Caldeira et al. (1999), avaliando o crescimento das leguminosas Dimorphandram acrostachya, Sclerolobium paniculatum e Peltogynevenos, inoculadas com FMAs, não encontraram diferença estatística para a variável diâmetro no estágio inicial das plantas. Enquanto Araújo (2012) observou crescimento linear para diâmetro de sabiá (Mimosa caesalpiniaefolia Benth.) aos 120 dias após o transplante em mudas que receberam inóculo de FMAs, a qual apresentou diâmetros significativamente superiores aos de todos os tratamentos que não receberam inoculação. Evidenciando-se, portanto, certa dependência do guanandi à condição micorrízica para crescimento em fase de viveiro.

Apesar do menor incremento relativo, a resposta na presença de FMAs foi superior, que pode ter ocorrido pela capacidade dos FMAs se estabelecerem e beneficiarem a planta hospedeira, na presença de $\mathrm{P}_{2} \mathrm{O}_{5}$ (BANUELOS, 2012).

Segundo Folli-Pereira et al., (2012), os fungos mais eficientes são aqueles que conseguem manter maior benefício à planta, sob maior gradiente de fósforo disponível no solo, denominado de faixa de mutualismo.

A faixa de mutualismo é compreendida pelos níveis de fósforo onde a simbiose mantém o benefício à planta e, segundo esses autores, apresenta relação direta com a eficiência do fungo. Nesse caso, quando comparamos a presença de FMAs em relação a sua ausência (Figura 4), observa-se que na presença de $\mathrm{P}_{2} \mathrm{O}_{5}$ esse mutualismo é contínuo, com tendência a linearidade dentro do intervalo de doses aplicado, até a dose de $2000 \mathrm{~g} \mathrm{~m}^{-3}$, que foi a maior dose testada (Figura 4).

Esse comportamento pode ser devido a efetividade simbiótica ser controlada pela eficiência do fungo, pela dependência da planta, que pode ser modulada pelo ambiente e do estado nutricional da planta, portanto, nas duas primeiras épocas o substrato estava mais fértil, consequentemente não havendo uma simbiose, podendo justificar não ter tido diferença estatística em altura.

Nunes et al., (2009) em trabalho realizado em produção de mudas de pessegueiro (Prunus persica) afirmam que as plantas inoculadas com fungos micorrízicos arbusculares (FMA) apresentaram maior crescimento em altura e diâmetro, diferindo significativamente das plantas sem inoculação.

Essa ausência de resposta para massa seca da raiz à inoculação com FMAs, sob doses de fósforo, é comum em outras espécies arbóreas (SUGAI et al. 2011).

Samarão et al. (2011) em pesquisa com gravioleira (Anonnam uricata L.) em inoculação com a espécie (FMAs) não constataram alterações significativas na biomassa do sistema radicular sob efeito de fungos. Por sua vez, Carneiro et al. (2004) estudando embaúba (Cecropia pachystachya) avaliando massa seca de raízes, verificaram aumento significativo nas raízes das plantas inoculadas em relação às plantas não inoculadas.

Trabalhos com respostas a aplicação de fósforo na formação de mudas em espécies florestais serem relativamente poucos, têm sido observado respostas à adubação fosfatada a produção de biomassa de espécies florestais nativas. Samarão et al., (2011) constataram incremento na matéria seca da parte aérea na dose $0,25,50$ e $100 \mathrm{mg} \mathrm{kg}{ }^{-1}$ de $\mathrm{P}_{2} \mathrm{O}_{5}$ em muda de gravioleira (Anonnam uricata L.).

$\mathrm{O}$ aumento na produção de massa seca pode estar ligado ao papel do fósforo na síntese de proteína, o qual reflete maior crescimento da planta. Lima et al., (2008) em estudo com diferentes doses do fósforo aplicado em muda de palmiteiro constatou crescimento na biomassa total das plantas.

Portanto a melhor dose a ser recomendada foi entre 1200 e $1600 \mathrm{~g}$, considerando que o diâmetro teve comportamento linear nas doses aplicadas, conforme verificou-se na Figura 2.

\section{CONCLUSÕES}

Em mudas de guanandi os diferentes níveis de adubação influenciam na colonização micorrízica com maior porcentagem de colonização nas doses $400 \mathrm{~g}$ e $1600 \mathrm{~g}$ de $\mathrm{P}_{2} \mathrm{O}_{5} \mathrm{~m}^{-3}$ de substrato.

A adubação com $\mathrm{P}_{2} \mathrm{O}_{5}$ na presença de fungos micorrízicos proporciona maiores incrementos em altura e diâmetro das mudas de guanandi.

O melhor desempenho das mudas de C. brasiliense ocorreu aos 90 dias com dose de $1.421 \mathrm{~g}$ de $\mathrm{P}_{2} \mathrm{O}_{5}$ por $\mathrm{m}^{3}$ de substrato.

\section{AGRADECIMENTOS}

Ao CNPq, Capes e a Universidade Federal do Tocantins, pelas bolsas de Mestrado, Doutorado e Iniciação Cientifica, concedidas aos autores.

\section{REFERÊNCIAS}

AGUIAR, R. L. F.; MAIA, L. C.; SALCEDO, I. H.; SAMPAIO, E. V. S. B. Interação entre fungos micorrízicos arbusculares e fósforo no desenvolvimento da algaroba (Prosopisjuliflora DC.). Revista Árvore, Viçosa, v. 28, n. 4, p. p. 589-598, 2004. http://dx.doi.org/10.1590/S0100-67622004000400013.

ARAÚJO, R. de S. L. Fungo micorrízico arbuscular e biofertilizantes no crescimento e nutrição da sabiá (Mimosa caesalpiniaefolia Benth.). 2012. $78 \mathrm{f}$. Dissertação (Programa de Pós-Graduação em Ciências Florestais) - Universidade Federal Rural de Pernambuco, Recife, Pernambuco, 2012.

BANUELOS, J.; TREJO, D.; ALARCON, A.; LARA, L.; MOREIRA, C.; CRUZ, S. The reduction in proline buildup in mycorrhizal plants affected by nematodes. Journal of Soil Science and Plant Nutrition. v. 12, n. 2, p. 263-270, 2012. DOI: https://dx.doi.org/10.4067/S071895162012000200006.

CALDEIRA, M. V. W.; SILVA, E. M. R.; FRANCO, A. A.; ZANON, M. L. B.; Efeito de fungos micorrízicos arbusculares no desenvolvimento de duas leguminosas arbóreas. Ciência Florestal, Santa Maria, v. 9, n. 1, p. 63-70, 1999.

CARNEIRO, M. A. C.; SIQUEIRA, J. O.; DAVIDE A. C. Fósforo e inoculação com fungos micorrízicos arbusculares no estabelecimento de mudas de embaúba (Cecropia pachystachya Trec). Pesquisa Agropecuária Tropical, Goiânia, v. 34, n. 3, p. 119-125, 2004.

CARNEIRO, R. F. V.; EVANGELISTA, A.R.; ARAÚJO, A. S. F. Crescimento vegetativo e aquisição de nutrientes 
pela alfafa em resposta à micorriza e doses de fósforo. Agrária, Recife, v. 4, p. 267-273, 2009.

CIRIELLO, V.; GUERRINI, I. A.; BACKES, C. Doses de nitrogênio no crescimento inicial e nutrição de plantas de guanandi. Cerne, Lavras, v. 20 n. 4 p. 653-660 2014 DOI: http://dx.doi.org/10.1590/01047760201420041445.

DANIEL, O.; VITORINO, A. C. T.; ALOVISI, A. A.; MAZZOCHIN, L.; TOKURA, A. M.; PINHEIRO, E. R. P.; SOUZA, E. F. Aplicação de fosforo em mudas de Acacia mangium willd. Revista Árvore, Viçosa, v. 21, n. 2, p. 163-168, 1997.

DUARTE, M. L.; PAIVA, H. N. de; ALVES, M. O.; FREITAS, A. F.; MAIA, F. F.; GOULART, L. M. L. Crescimento e qualidade de mudas de Vinhático (Platymenia foliolosa Benth.) em resposta à adubação com potássio e enxofre. Ciência Florestal, Santa Maria, v. $25, \quad$ p. 221-229, 2015. DOI: http://dx.doi.org/10.5902/1980509817480.

FERREIRA, D. F. SISVAR - Sistema de análise de variância. Versão 5.3. Lavras-MG: UFLA, 2010.

FREITAS, M. S. M.; MARTINS, M. A.; CARVALHO, A. J. C. Crescimento e composição mineral da menta em resposta à inoculação com fungos micorrízicos arbusculares e adubação fosfatada. Horticultura Brasileira, Brasília, v. 24, n. 1, p.11-16, 2006.

FOLLI-PEREIRA, M. S.; MEIRA-HADDAD, L.S.; BAZZOLI, D. M. S.; KASUYA, M.C.M. Micorriza arbuscular e a tolerância das plantas ao estresse. Revista Brasileira de Ciência do Solo, Viçosa, v. 36, p. 10831091, 2012.

KOSKE, R. E.; GEMMA, J. N. A modified procedure for staining roots to detect VA mycorrhizas. Mycological Research, v. 92, n. 4, p. 486-488, 1989.

LACERDA, K. A. P.; SILVA, M. M. S.; CARNEIRO, M. A. C.; REIS, E. F.; JÚNIOR, O. J. S. Adubação fosfatada no crescimento inicial de seis espécies arbóreas do cerrado. Cerne, Lavras, v. 17, n. 3, p. 377-386. 2011.

LIMA, L. S. H.; FRANCO, E. T. H.; SCHUMACHER, M. V. Crescimento de mudas de Euterpe edulis Martius em resposta a diferentes doses de fósforo. Ciência Florestal, Santa Maria, v. 18, p. 461-470, 2008.

LISBOA, A. C.; SANTOS, P. S.; OLIVEIRA NETO, S. N.; CASTRO, D. N.; ABREU, A. H. M. Efeito do volume de tubetes na produção de mudas de Calophyllum brasiliense e Toona ciliata. Revista Árvore, Viçosa, v. 36, n. 4, p. 603-609, 2012. DOI: http://dx.doi.org/10.1590/S0100-67622012000400003.

LUCENA, V. B.; RAIMAN, M. P.; CARDOSO, N. A.; ALBINO, U. B. Influência de Fungos Micorrizicosarbusculares em paricá (Shcizolobium amazonicum) cultivado no estado do Pará. Pesquisa Florestal Brasileira, Colombo, v. 33, p. 235-271, 2013.
MALAVOLTA, E. ABC da adubação. São Paulo: Agronômica Ceres, 1989. p 292.

MUNIER-LAMY, C.; DENEUX-MUSTIN, S.; MUSTIN, C.; MERLET, D.; BERTHELIN, J.; LEYVAL, C. Selenium bioavailability and uptake as affected by four different plants in a loamy clay soil with particular attention to mycorrhizae inoculated ryegrass. Journal of Environmental Radioactivity, v. 97, p. 148-158, 2007.

NOVAIS, R. F.; SMITH, T. J.; Fósforo em solo e planta em condições tropicais. Viçosa: UFV-DPS. 1999, 399p.

NUNES, J. L. S.; SOUZA, P. V. D.; BETTIO M, G. A.; FACHINELLO, J. C. Eficiência de fungos micorrízicos arbusculares sobre o crescimento do porta-enxerto de pessegueiro 'aldrighi. Bragantia, Campinas, v. 68, n. 4, p. 931-940, 2009.

PARON, M. E.; SIQUEIRA, J. O.; CURI, N. Fungo micorrízico, fósforo e nitrogênio no crescimento inicial da trema e do fedegoso. Revista Brasileira Ciência Solo, Viçosa, v. 21, n. 4, p. 567-574. 1997.

SAMARÃO, S. S.; RODRIGUES, A. L.; MARTINS, A. M.; MANHÃES, N. T.; ALVIM, M. L. Desempenho de mudas de gravioleira inoculadas com fungos micorrízicos arbusculares em solo não-esterilizado, com diferentes doses de fósforo. Acta Scientiarum Agronomy, Maringá, v. 33, n. 1, p. 81-88, 2011. DOI: http://dx.doi.org/10.4025/actasciagron.v33i1.5427.

SCHORN, L. A. Silvicultura II Produção de mudas florestais. Apostila Universidade Regional de Blumenau Centro de Ciência Tecnológica. Departamento de Engenharia Florestal, Blumenau, 2003.

SILVA, F. R.; ANTONIOLLI, Z. I.; Ocorrência de fungos micorrízicos em espécies florestais na região central do Estado do rio grande do sul. Revista Brasileira Agrociência, Pelotas, v. 15, n. 1-4, p. 65-70. 2009.

SOUZA, F. A.; GOMES, E. A.; VASCONCELOS, M. J. V.; SOUSA, S. M. Micorrizas arbusculares: Perspectivas para aumento da eficiência de aquisição de fósforo $(P)$ em Poaceae - Gramíneas. Sete Lagoas: Embrapa Milho e Sorgo, 2011.

SUGAI, M. A. A.; COLLIER. L. S.; SAGGIN-JUNIOR, O. J. Inoculação micorrízica no crescimento de mudas de angico em solo de cerrado. Bragantia, Campinas, v. 70, n. 2, p. 416-423, 2011.

TRAZZI, P. A.; CALDEIRA, M. V. W.; COLOMBI, R.; GONÇALVES, E. O. Qualidade de mudas de Murraya paniculata produzidas em diferentes substratos. Revista Floresta, Curitiba, v. 42, n. 3, p. 621-630, 2012. DOI: http://dx.doi.org/10.5380/rf.v42i3.19718. 